\title{
Identification of two contiguous minimally deleted regions on chromosome Ip36.3 I-p36.32 in oligodendroglial tumours
}

\author{
Z Dong', JC-S Pang', MH Ng', WS Poon ${ }^{2}$, L Zhou ${ }^{3}$ and H-K Ng*,I \\ 'Department of Anatomical and Cellular Pathology, Prince of Wales Hospital, The Chinese University of Hong Kong, Hong Kong, China; ${ }^{2}$ Neurosurgical \\ Unit, Department of Surgery, Prince of Wales Hospital, The Chinese University of Hong Kong, Hong Kong, China; ${ }^{3}$ Department of Neurosurgery, Hua \\ Shan Hospital, Fudan University, Shanghai, China
}

\begin{abstract}
Loss of the short arm of chromosome $\mathrm{I}$ is a hallmark of oligodendroglial tumours (OTs). Deletion mapping studies in OTs have revealed multiple commonly deleted regions on chromosome I $\mathrm{p}$, suggesting that there are more than one tumour suppressor gene. To map critical deletion regions on Ip, a series of 25 OTs were examined for loss of heterozygosity (LOH) on 19 polymorphic markers across the Ip arm using microsatellite analysis. Our study revealed that $60 \%$ of tumours had LOH of all informative markers on I p and identified one tumour showing $\mathrm{LOH}$ at telomeric markers only. Since this deletion region lies in one of the critical deletion intervals defined previously, we then screened another series of 27 OTs specifically at Ip36.3 for LOH using nine polymorphic markers. A total of $12 \%$ (six out of 52) of tumours were found to carry interstitial deletions. The allelic status and the deletion breakpoints in these tumours with interstitial deletion were further verified by fluorescent in situ hybridisation. The small overlapping intervals facilitated the delineation of two contiguous minimally deleted regions of $0.76 \mathrm{Mb}$, defined by DIS468 and DIS2845, and of $0.4 \mathrm{I} \mathrm{Mb}$, bound by DIS2893 and DISI 608, on I 36.3 I - 36.32. Based on current reference human genome sequence these deletion regions have been sequenced almost to entirety and contain eight annotated genes. TP73, DFFB and SHREWI are the only known genes located in these deletion regions, while the others are uncharacterised novel genes. In conclusion, our study has narrowed down the critical tumour suppressor loci on I 36.3, in which two minimally deleted regions are mapped, and markedly reduced the number of candidate genes to be screened for their involvement in OT development.

British Journal of Cancer (2004) 91, I I05- I III. doi: I0.1038/sj.bjc.6602093 www.bjcancer.com
\end{abstract}

(C) 2004 Cancer Research UK

Keywords: oligodendroglioma; oligoastrocytoma; tumour suppressor gene; loss of heterozygosity; chromosome Ip

Oligodendroglial tumours (OTs) are primary brain neoplasms that constitute about $5-18 \%$ of all gliomas. These tumours comprise the classic oligodendrogliomas and mixed oligoastrocytomas. Two malignancy grades are recognised by the World Health Organization (WHO): grade II for the well-differentiated tumours and grade III for the anaplastic variants (Reifenberger et al, 2000). Unlike other glioma types, OTs have a unique clinical feature of remarkable responsiveness to chemotherapy (Macdonald et al, 1990; Perry et al, 1999).

The pathogenesis of OTs is poorly understood. Molecular studies have shown that allelic deletions of chromosome arms 1p and $19 q$ are the most frequent genetic alterations in OTs, suggesting that these chromosomes carry critical tumour suppressor genes and their inactivation is involved in the early stage of OT development (Bello et al, 1995). The frequencies of allelic loss of $1 \mathrm{p}$ and $19 \mathrm{q}$ in OTs are 67-94 and 70-76\%, respectively, and of combined losses is 64-72\% (Bello et al, 1995; Bigner et al, 1999; Husemann et al, 1999; Jeuken et al, 1999; Smith et al, 1999; Iuchi et al, 2002). Other genetic alterations occurring at lower frequencies include losses of chromosomes 4, 9, 10,14, 15 and 18 (Bigner et al, 1999; Jeuken et al, 1999). With regard to target

*Correspondence: Professor H-K Ng; Email: hkng@cuhk.edu.hk Received 23 February 2004; revised 28 April 2004; accepted 22 June 2004 genes, the CDKN2A tumour suppressor gene located on 9p21 is found to be homozygously deleted in about $25 \%$ of anaplastic oligodendrogliomas (Cairncross et al, 1998; Bigner et al, 1999; Watanabe et al, 2001a) and the PTEN gene maps to 10q23 is mutated in $8 \%$ of anaplastic oligodendrogliomas (Sasaki et al, 2001). In addition, recent studies have shown that epigenetic change also plays an important role in OT formation. Promotor hypermethylation of RB1 and $\mathrm{p} 14^{\mathrm{ARF}}$ is detectable, respectively, in $34 \%$ (Dong et al, 2001; Watanabe et al, 2001b) and $18-41 \%$ (Watanabe et al, 2001a, Wolter et al, 2001; Alonso et al, 2003) of OTs. Taken together, these results suggest that at least three genetic pathways involving CDKN2A/RB1, p14 ${ }^{\mathrm{ARF}} / \mathrm{p} 53$ and PTEN/ $\mathrm{PI} 3 \mathrm{~K}-\mathrm{AKT}$ are dysregulated in OT development. On contrary, the target genes from the frequently deleted chromosome arms $1 \mathrm{p}$ and $19 \mathrm{q}$ are not yet identified.

The majority of OTs harbouring $1 \mathrm{p}$ deletion show allelic loss in all informative markers, indicating that entire or most of short arm has been deleted. Hence, the deletion breakpoints on $1 p$ have been derived from a limited number of tumours carrying small deletions (Reifenberger et al, 1994; Bello et al, 1995; Zhu et al, 1998b; Husemann et al, 1999; Smith et al, 1999; Iuchi et al, 2002). Husemann et al (1999) identified two distinct regions of loss from three OTs carrying interstitial deletions: a distal region between D1S76 and D1S253 at $1 \mathrm{p} 36.3(\sim 5 \mathrm{Mb})$ and a proximal region between D1S482 and D1S2743 (17 Mb) at 1p34.2-p36.12. Smith 
et al (1999) mapped a commonly deleted region to $1 \mathrm{p} 36.31-\mathrm{p} 36.32$ (3.7 Mb) between D1S468 and D1S1612, whereas Iuchi et al (2002) delineated two regions of loss to $1 \mathrm{p} 34-\mathrm{p} 35(\sim 5.7 \mathrm{Mb})$ and $1 \mathrm{p} 36.1-\mathrm{p} 36.2(\sim 12 \mathrm{Mb})$. These deletion regions do overlap and may be refined to three loci: 1p36.3 (between D1S468 and D1S253 of $\sim 2.9 \mathrm{Mb}$ ), $1 \mathrm{p} 36.1$ (between D1S482 and D1S1676 of $1.4 \mathrm{Mb}$ ) and 1 p34.3 - p35 (between D1S247 and D1S496 of $4.4 \mathrm{Mb}$ ) (Figure 1). The identification of multiple deletion regions suggests that there is more than one tumour suppressor gene on the $1 \mathrm{p}$ arm. The possibility of multiple tumour suppressor loci on $1 \mathrm{p}$ has also been suggested from studies of other tumour types such as meningiomas (Bello et al, 2000b). Two candidate genes, CDKN2C (1p32.3) and hRAD54 (1p34.1-p33) were evaluated for their involvement in OT. Somatic mutation and homozygous deletion of CDKN2C was detected in $2-5 \%$ anaplastic oligodendrogliomas, suggesting alteration of this gene is involved in progression of a subset of tumours (Husemann et al, 1999; Pohl et al, 1999; He et al, 2000). No base alterations were, however, found in hRAD54 (Bello et al, 2000a).

Recent studies have also demonstrated that allelic loss of $1 \mathrm{p}$ is closely associated with chemosensitivity and better prognosis in patients with anaplastic oligodendrogliomas (Cairncross et al, 1998; Ino et al, 2001). Thus, investigation into the basis of $1 \mathrm{p}$ loss would unveil not only the pathogenesis of OT, but might also provide insights into the genetic origin of these clinical responses. In this study, we reported the refinement of one of the critical deletion regions in OT to $1 \mathrm{p} 36.31-36.32$ and the mapping of two contiguous minimally deleted regions, in which there are only eight genes annotated.

\section{MATERIALS AND METHODS}

\section{Tumour specimens and DNA extraction}

A cohort of 52 OTs, including 22 oligodendrogliomas (WHO grade II), 14 anaplastic oligodendrogliomas (WHO grade III), 13 oligoastrocytomas (WHO grade II) and three anaplastic oligoastrocytomas (WHO grade III), and their corresponding blood samples were obtained from Prince of Wales Hospital, Hong Kong and Hua Shan Hospital, Shanghai, China. The OTs were classified according to the current WHO Classification of Tumours of Nervous System (Reifenberger et al, 2000). Histological assessment of tissue sections confirmed a tumour cell content of at least $80 \%$ in all samples. The average age of patients was $40.8 \pm 15.3$ years (range, 8-74) and the male/female ratio was $1.4: 1$.

DNA was prepared from tissue and blood specimens using the conventional proteinase $\mathrm{K}$ digestion and phenol/chloroform extraction method. DNA extracted from blood leukocytes was used as constitutional control.

\section{Microsatellite analysis}

A total of 30 microsatellite loci, located on chromosome arms 1p, $1 \mathrm{q}$ and $19 \mathrm{q}$, were investigated for loss of heterozygosity (LOH) according to reported protocol (Tong et al, 2001). In all, 26 polymorphic markers map to $1 \mathrm{p}$ arm (D1S171, D1S468, D1S2845, D1S2893, D1S2660, D1S1608, D1S2132, D1S2795, D1S2870, D1S1646, D1S1612, D1S2667, D1S2647, D1S482, D1S470, D1S496, D1S2743, D1S2724, D1S2752, D1S473, D1S1665, D1S2807, D1S188, D1S2808, D1S2695 and D1S514), two markers map to 1q arm (D1S215 and D1S2625) and two markers locate to chromosome 19q (D19S219 and D19S412). These markers were labelled either with fluorochrome FAM or HEX (Proligo, Singapore). Briefly, polymerase chain reaction (PCR) was performed in a final volume of $5 \mu \mathrm{l}$ containing $50-100 \mathrm{ng}$ of DNA, $10 \mathrm{~mm}$ Tris- $\mathrm{HCl}(\mathrm{pH} \mathrm{8.3)}$, $50 \mathrm{mM} \mathrm{KCl}, 2.5 \mathrm{mM} \mathrm{MgCl}_{2}, 0.2 \mathrm{~mm}$ deoxyribonucleoside triphosphates, $0.5 \mathrm{U}$ of AmpliTaq Gold DNA polymerase (Applied

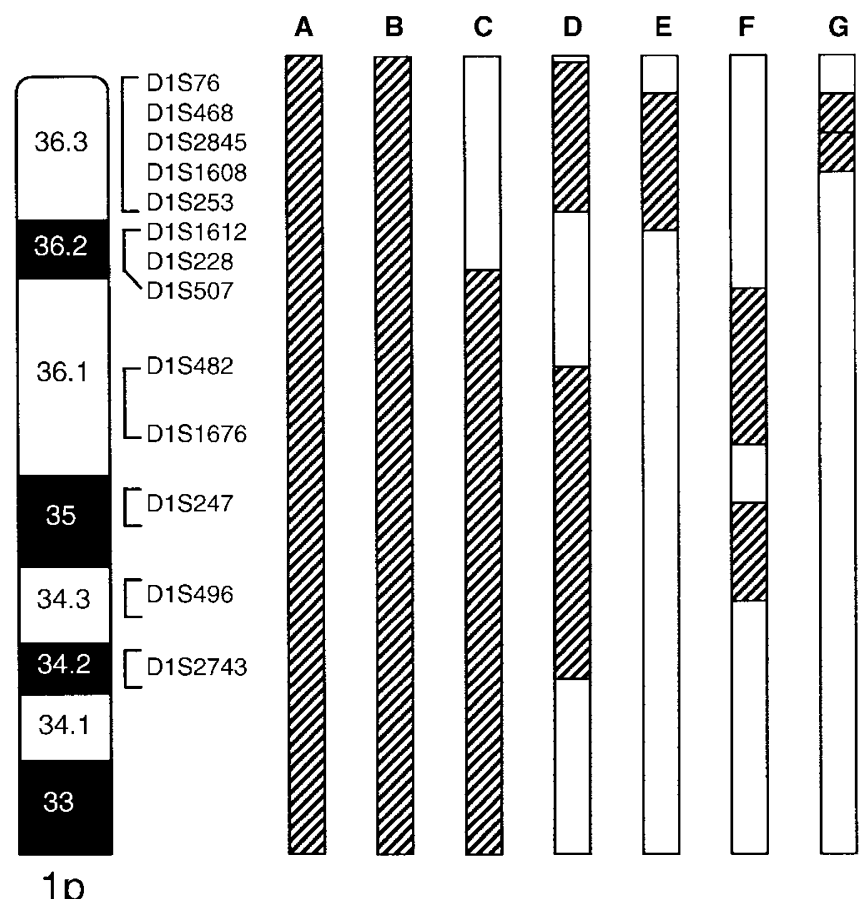

Figure I Deletion mapping studies of chromosomal arm Ip in OTs. (A) Reifenberger et al (1994); (B) Bello et al (1995); (C) Zhu et al (I998b); (D) Husemann et al (1999); (E) Smith et al (1999); (F) luchi et al (2002); (G) current study. Striped bars represent minimally deleted regions identified in each study.

Biosystems, Foster City, USA), and $0.4 \mu \mathrm{M}$ of each primer. The PCR commenced with an enzyme activation step at $95^{\circ} \mathrm{C}$ for $10 \mathrm{~min}, 40$ cycles of $94^{\circ} \mathrm{C}$ for $1 \mathrm{~min}, 55-60^{\circ} \mathrm{C}$ for $1 \mathrm{~min}$ and $72^{\circ} \mathrm{C}$ for $1 \mathrm{~min}$, and finalised with an elongation step at $72^{\circ} \mathrm{C}$ for $10 \mathrm{~min}$. PCR products of multiple markers were pooled and electrophoresed in denaturing $4 \%$ polyacrylamide gels using an ABI Prism 377 automated DNA sequencer (Applied Biosystems). The data collected were analysed using GeneScan Analysis software version 3.1 (Applied Biosystems). Allelic imbalance was defined by calculating the allelic ratio of both normal $(\mathrm{N})$ and tumour $(\mathrm{T})$ DNA, based on the formula of $(\mathrm{N} 2 / \mathrm{N} 1) /(\mathrm{T} 2 / \mathrm{T} 1)$, where $\mathrm{N} 2$ or $\mathrm{T} 2$ represents the peak height of the longer allele and $\mathrm{N} 1$ or $\mathrm{T} 1$ represents the peak height of the shorter allele. $\mathrm{LOH}$ was inferred when the allelic ratio was greater than 1.5 or smaller than 0.5 , representing loss of the shorter or longer allele, respectively.

\section{FISH}

Dual-colour FISH analysis was performed on formalin-fixed paraffin-embedded tissue sections as reported with modification (Jenkins et al, 1997). Section of 5 - $\mu \mathrm{m}$ thickness were deparaffinised, dehydrated, treated with sodium thiocyanate at $80^{\circ} \mathrm{C}$ for $10 \mathrm{~min}$, digested in pepsin solution $\left(5 \mathrm{mg} \mathrm{ml}^{-1}\right.$ in $\left.0.2 \mathrm{~N} \mathrm{HCl}\right)$ for 20-30 min, rinsed in phosphate-buffered saline and dehydrated. The sections were then treated with microwave $(600 \mathrm{~W})$ in citrate buffer ( $\mathrm{pH} \mathrm{6.0)}$ ) for $10 \mathrm{~min}$, baked at $80^{\circ} \mathrm{C}$ for $30 \mathrm{~min}$ and subjected to hybridisation.

Seven bacterial artificial chromosomes (BACs) or bacteriophage P1-derived artificial chromosomes (PACs) were labelled to generate locus-specific FISH probes. These included six target probes for $1 \mathrm{p}$ arm and one reference probe for $1 \mathrm{q} 32$ (BAC clone RP11-79I9 encompassing the marker STSG28964). The genomic clones were purchased from Invitrogen Corporation (Carlsbad, 
USA). DNA was labelled by nick-translation in a reaction containing $100 \mathrm{~mm}$ Tris- $\mathrm{HCl}(\mathrm{pH} 7.5), 10 \mathrm{mM} \mathrm{MgCl}_{2}, 0.01 \%$ bovine serum albumin, $0.1 \mathrm{~mm}$ dATP, $0.1 \mathrm{~mm}$ dCTP, $0.1 \mathrm{~mm}$ dGTP, $0.1 \mathrm{~nm}$ dTTP, $0.1 \mathrm{~nm} \beta$-mercaptoethanol, $0.03 \mathrm{U}$ DNase I, $20 \mathrm{U}$ of DNA polymerase I, and $0.85 \mathrm{nmol}$ of digoxigenin-1-dUTP (for target probe) or $1.9 \mathrm{nmol}$ of biotin-16-dUTP (for reference probe) (Roche Diagnostics Ltd., Hong Kong) at $15^{\circ} \mathrm{C}$ for $25-45 \mathrm{~min}$. The labelled probes were mixed with fish sperm and Cot-1 DNA in Hybrisol VI solution (Appligene Oncor, Illkirch Graffenstaden, France), denatured and applied onto sections. Hybridisation was carried out at $37^{\circ} \mathrm{C}$ overnight. Sections were washed with $1.5 \mathrm{M}$ urea/ $1 \times$ saline sodium citrate (SSC) at $45^{\circ} \mathrm{C}$ for $30 \mathrm{~min}, 2 \times \mathrm{SSC}$ at $45^{\circ} \mathrm{C}$ for $15 \mathrm{~min}$, treated with either antidigoxigenin-rhodamine antibody (Sigma) or avidin conjugated-fluorescein isothiocyanate (Vector Laboratories, Burlingame, USA) at $37^{\circ} \mathrm{C}$ for $1.5 \mathrm{~h}$, washed in phosphate-buffered saline detergent (Appligene Oncor), and counterstained with Vectashield mounting medium with anti-fade solution of 4,6-diamidino-2phenylindole (DAPI; Vector Laboratories).

Sections were viewed under a Zeiss Axioplan microscope and images of rhodamine, FITC and DAPI were captured through a triple-pass filter by a cooled charge-coupled device. A total of 200 nonoverlapping tumour nuclei were counted on each section. A sample was considered having deletion of $1 \mathrm{p}$ locus when more than $70 \%$ of counted nuclei exhibited one target signal (red) and two reference signals (green).

\section{Statistical analysis}

Statistical analysis was performed using the software SPSS 10.0. The correlation between two parameters was evaluated by $\chi^{2}$-test or Fisher's exact test, whichever was appropriate. An obtained $P$ value less than 0.05 (two-sided) was considered statistical significant.

\section{RESULTS}

\section{Deletion mapping on chromosome 1p}

To localise tumour suppressor loci on the short arm of chromosome 1 in OTs, we carried out a deletion mapping study across the entire $1 \mathrm{p}$ arm using microsatellite analysis. A series of 25 OTs were investigated for $\mathrm{LOH}$ at 19 microsatellite loci, spacing at an average interval of $7 \mathrm{Mb}$ on the $1 \mathrm{p}$ arm. Each tumour showed informativeness in at least seven markers. Overall, $15(60 \%)$ tumours demonstrated $\mathrm{LOH}$ in at least one marker, with 14 of them showing LOH at all informative markers tested suggesting that these tumours had lost a copy of the entire or most of $1 \mathrm{p}$ arm. One tumour (A18) showed LOH at D1S468 and its juxtaposed marker D1S2795, both of which map to the telomeric end of 1p36.3, but retained heterozygosity at all informative markers centromeric to D1S2795 (Figure 2). This deletion segment lies in the overlapped region of loss defined by Smith et al (1999) and Husemann et al (1999), indicating that 1p36.3 is a critical region involved in OT development. Since tumours with small chromosomal deletion are useful in delineation of tumour suppressor loci, we subsequently characterised another series of OTs focusing specifically at the 1 p36.3 region with an aim to obtain additional cases harbouring interstitial deletion. We evaluated the allelic status of a total of nine (with seven additional new markers) polymorphic markers on $1 \mathrm{p} 36.3$ in a second series of 27 OTs and also in those tumours of the first series that showed small terminal deletion (i.e. case A18) or no LOH. The average interval between these nine markers is $0.46 \mathrm{Mb}$. In the second series, each tumour showed informativeness in at least three markers. Totally, 17 (63\%) OTs demonstrated $\mathrm{LOH}$ in at least one marker, with 13 of them showing $\mathrm{LOH}$ at all informative markers. Four tumours (B9, B14, B26 and B27) exhibited $\mathrm{LOH}$ patterns suggestive of interstitial deletion. Cases B9, B14 and B26 lost heterozygosity at single marker, D1S2660 or D1S2845, while retaining balanced alleles at other informative loci. B27 showed $\mathrm{LOH}$ at two contiguous markers, D1S2660 and D1S1608, and maintained allelic balance at D1S2795, which is $0.69 \mathrm{Mb}$ proximal to D1S1608. Other markers were noninformative in this tumour. In addition, our finer mapping has identified one more tumour (A19) with interstitial deletion from the initial set of tumours that showed no LOH. A19 had lost heterozygosity at D1S2845 on 1p. Surprisingly, A18 which initially displayed a telomeric deletion at $1 \mathrm{p}$ showed a zebra $\mathrm{LOH}$ pattern upon finer mapping. $\mathrm{LOH}$ was demonstrated at distal markers D1S171 and D1S468 and at proximal markers from D1S1608 to D1S2795, while allelic balanced markers were detected between these two regions and centromeric to D1S2795. This result suggests that A18 harbours two interstitial deletions on 1p36.3.

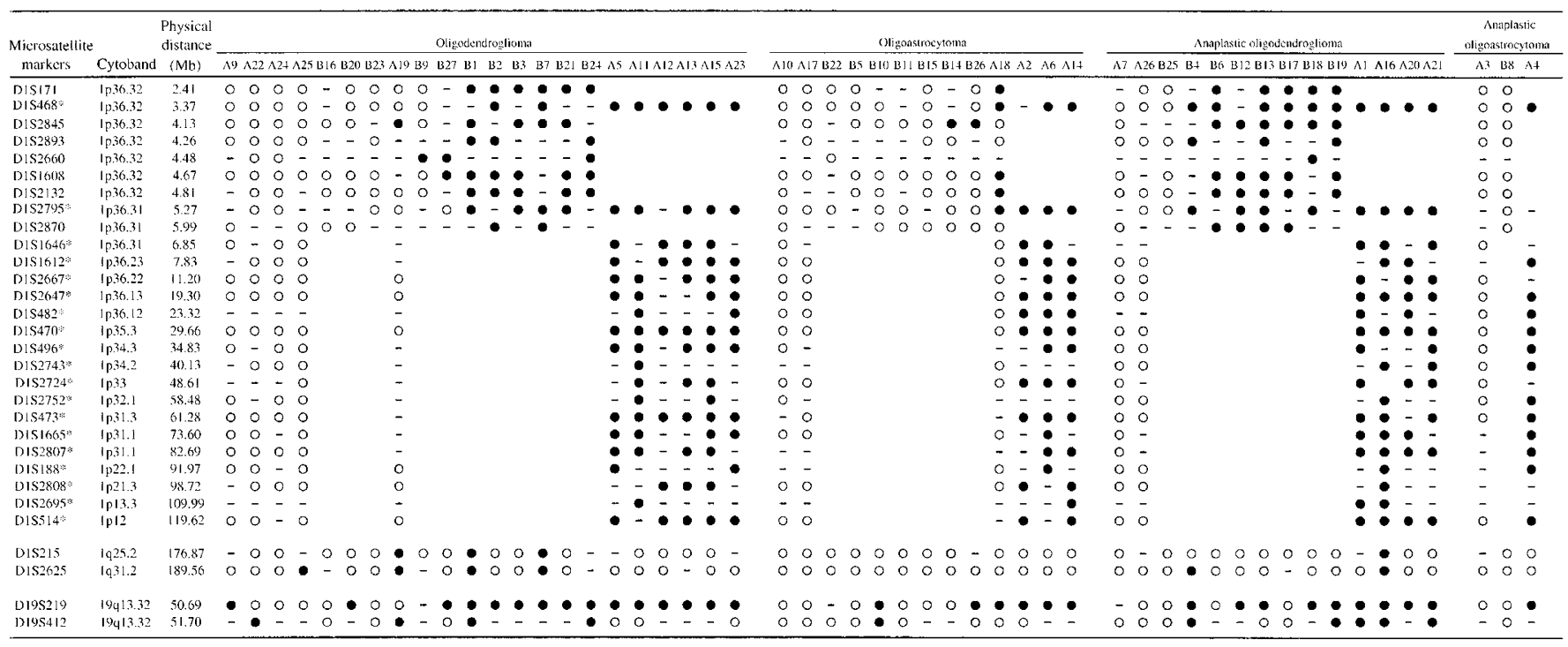

Figure 2 Summarised results of microsatellite analysis of 52 OTs examined. Cytoband and physical distance of microsatellite markers were derived from current reference human genome sequence (Build 34). The asterisks represent markers examined in the first round of microsatellite analysis. Filled circle $=\mathrm{LOH}$; open circle $=$ retention of heterozygosity; $-=$ noninformative. 
Taken together, allelic loss of $1 \mathrm{p}$ was detected in 15 out of $22(68 \%)$ oligodendrogliomas, 11 out of $14(79 \%)$ anaplastic oligodendrogliomas, six out of $13(46 \%)$ of oligoastrocytomas, and one out of three (33\%) anaplastic oligoastrocytomas. Tumours with interstitial deletion on $1 \mathrm{p} 36.3$ constitute $12 \%$ (six out of 52 ) of all OTs examined.

\section{Determination of deletion breakpoints on $1 \mathrm{p} 36.3$}

We then employed an independent assay, interphase FISH, to verify the allelic status and to determine the deletion breakpoints in tumours that showed interstitial deletion. Four cases (A18, A19, B9 and B14), for which tissues were available, were subjected to FISH. Representative results of FISH are shown in Figure 3. Tumours were scored as having $\mathrm{LOH}$ when more than $70 \%$ of counted nuclei showed single target signal and two reference signals. Figure 4 summarises the allelic status, determined by both microsatellite and FISH analyses, of six OTs that showed interstitial deletion at $1 \mathrm{p} 36.3$. Concordant results were obtained for both techniques. Moreover, FISH revealed the allelic status of six more markers among the four tumours examined. Based on these data, two minimally deleted regions (MDRs) are delineated. MDR1 maps to a region of $0.76 \mathrm{Mb}$, defined by D1S468 and D1S2845, and MDR2 locates to an interval of $0.41 \mathrm{Mb}$, bound by D1S2893 and D1S1608.

\section{Genes annotated in MDRs}

Based on the latest version of reference human genome sequence (Build 34, July 2003 freeze) the MDRs are covered by two sequence contigs (NT_004321 and NT_004547) with a gap of suggested size of $50 \mathrm{~kb}$ between these contigs. MDR1 starts from D1S468, which locates about $230 \mathrm{~kb}$ to the proximal end of NT_004321, spans over the sequence gap and ends at D1S2845, which is $480 \mathrm{~kb}$ from the distal end of NT_004547, whereas MDR2 lies in NT_004547. There are seven annotated genes clustered at the distal region of MDR1 on NT_004321 (Table 1). However, in a genomic interval of about $1 \mathrm{Mb}$ covering the proximal region of MDR1 to end of MDR2, there is only one single gene identified, SHREW1.

\section{Allelic statuses of $1 \mathrm{q}$ and $19 q$}

Two loci, D1S215 (1q25.2) and D1S2625 (1q31.2), were investigated for $\mathrm{LOH}$ on $1 \mathrm{q}$ arm. All tumours except case B24 were informative at either or both markers. Three tumours (A16, B1 and B7) had lost heterozygosity at both markers on $1 \mathrm{q}$ and also at all informative markers on $1 \mathrm{p}$, suggesting that the entire chromosome was lost. Allelic loss of both 1q markers was also observed in tumour A19,

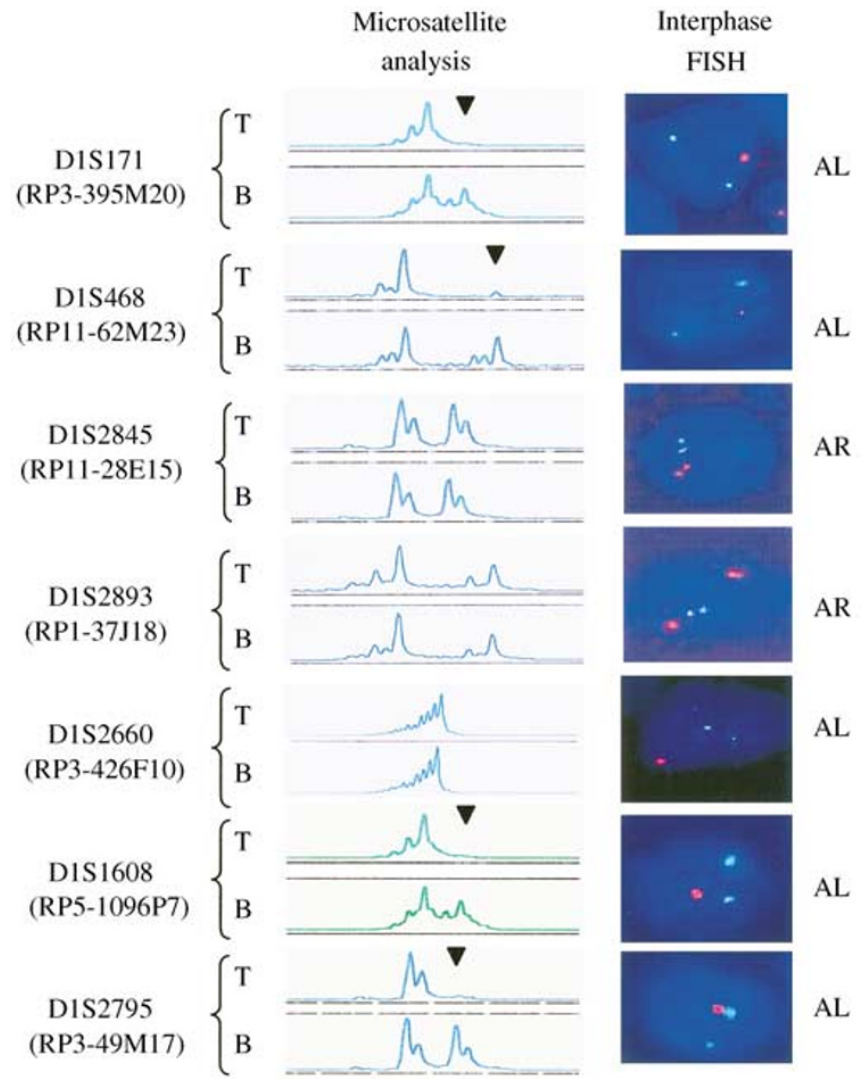

Figure 3 Representative results of microsatellite and interphase FISH analyses of case AI8. Microsatellite markers are indicated on left with corresponding BAC or PAC clones containing such markers in parentheses. Concordant results are obtained for both techniques. Of note is that FISH reveals allelic loss at the noninformative locus DIS2660. Allelic loss (AL) in microsatellite analysis is indicated by arrowhead and is represented by one red (target) signal and two green (chromosome I centromere) signals in FISH. Allelic retention (AR) is indicated by the presence of both alleles in microsatellite analysis and is represented by two red and two green signals. $\mathrm{T}=$ tumour; $\mathrm{B}=$ tumour-matched blood

\begin{tabular}{|c|c|c|c|c|c|c|c|c|c|}
\hline \multirow{3}{*}{$\begin{array}{l}\text { Microsatellite } \\
\text { marker }\end{array}$} & \multirow{3}{*}{$\begin{array}{c}\text { Physical } \\
\text { distance } \\
(\mathrm{Mb})\end{array}$} & \multirow{3}{*}{$\begin{array}{l}\mathrm{BAC} / \mathrm{PAC} \\
\text { clone }\end{array}$} & \multicolumn{6}{|c|}{ Case number/tumour subtype } & \\
\hline & & & $\mathrm{B} 26$ & A19 & B14 & A18 & B27 & B9 & \\
\hline & & & $\mathrm{OA}$ & $\mathrm{O}$ & $\mathrm{OA}$ & $\mathrm{OA}$ & $\mathrm{O}$ & $\mathrm{O}$ & \\
\hline D1S171 & 2.41 & - & 0 & O & - & 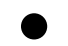 & - & O & \\
\hline D1S468 & 3.37 & RP11-62M23 & 0 & $0^{*}$ & * & & - & $\bigcirc$ & MDR1 \\
\hline D1S2845 & 4.13 & RP11-28E15 & 0 & $0^{*}$ & * & $\bigcirc^{*}$ & - & $\bigcirc^{*}$ & $0.76 \mathrm{Mb}$ \\
\hline D1S2895 & 4.26 & RP1-37J18 & - & $0^{*}$ & $\bigcirc^{*}$ & $\mathrm{O}^{*}$ & - & $0^{*}$ & \\
\hline D1S2660 & 4.48 & RP3-426F10 & 一 & $\mathrm{O}^{*}$ & 一 & 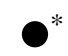 & O & * & $\begin{array}{c}\text { MDK2 } \\
0.41 \mathrm{Mb}\end{array}$ \\
\hline D1S1608 & 4.67 & RP5-1096P7 & O & $0^{*}$ & O & & 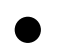 & $0^{*}$ & \\
\hline D1S2132 & 4.81 & - & 0 & 0 & O & & - & 0 & \\
\hline D1S2795 & 5.27 & RP3-491M17 & $\bigcirc$ & $0^{*}$ & O & & O & - & \\
\hline D1S2870 & 5.99 & - & 0 & - & 0 & 0 & - & - & \\
\hline
\end{tabular}

Figure 4 Delineation of MDRs on I 36.3 in OTs by combined microsatellite and FISH analyses. FISH revealed the allelic status of six noninformative polymorphic markers (DIS2893, DIS2660 and DISI608 in AI9; DIS468 in BI4; DIS2660 in AI8; and DIS2893 in B9). The solid bars represent MDRs. $\mathrm{O}=$ oligodendroglioma $\mathrm{WHO}$ grade $\|$; $\mathrm{OA}=$ oligoastrocytoma $\mathrm{WHO}$ grade $\|$; filled circle $=\mathrm{LOH}$; open circle= retention of heterozygosity; = noninformative; * allelic status confirmed or revealed by FISH. 
Table I A list of annotated genes mapped between DIS468 and DISI608 on chromosome Ip36.3

\begin{tabular}{|c|c|c|c|c|}
\hline Locus & Gene $^{a}$ & Accession no. & Domain ${ }^{b}$ & Biological function \\
\hline & TP73 & NM_005427 & $\begin{array}{l}\text { p53 } \\
\text { Sterile alpha motif }\end{array}$ & $\begin{array}{l}\text { Transactivates p53 target genes, suppresses cell proliferation and induces apoptosis } \\
\mathrm{N} \text {-terminally truncated isoforms have anti-apoptotic functions }\end{array}$ \\
\hline & FLJ32825 & NM_I 52492 & Chromosome segregation ATPase & Hypothetical protein with unknown function \\
\hline & KIAAII 85 & NM_0207I0 & $\begin{array}{l}\text { Leucine-rich repeat } \\
\text { Phenylalanyl-tRNA synthetase }\end{array}$ & Hypothetical protein with unknown function \\
\hline & LOC339448 & XM_290902 & Unknown & Hypothetical protein with unknown function \\
\hline \multirow{3}{*}{\multicolumn{5}{|c|}{$\begin{array}{l}\text { DIS2845 } \\
\text { DIS2893 } \\
\text { DIS2660 }\end{array}$}} \\
\hline & & & & \\
\hline & & & & Binds to E-cadherin and $\beta$-catenin in adherens junctions in polarised epithelial cells \\
\hline DISI608 & & & & \\
\hline
\end{tabular}

${ }^{a}$ Based on reference human genome sequence Build 34. 'based on LocusLink (http://www.ncbi.nlm.nih.gov/LocusLink) and InterProScan (http://www.ebi.ac.uk/interpro).

which harboured interstitial deletion of $1 \mathrm{p}$ at D1S2845. B4 had lost heterozygosity at distal marker D1S2625 but maintained allelic balance at D1S215, whereas A25 showed LOH at D1S2625 and was noninformative at D1S215. Together, six out of 51 (12\%) informative OTs exhibited LOH on 1q.

Two markers, D19S219 and D19S412, which are $1.02 \mathrm{Mb}$ apart and locate in the common region of deletion on 19q13.3 were investigated for allelic loss. Out of 51,33 (65\%) informative tumours exhibited $\mathrm{LOH}$ in at least one of the $19 \mathrm{q}$ markers. In all, 10 tumours (A2, A5, A11, A18, A19, A22, A23, B13, B26 and B27) had lost heterozygosity at either marker but maintained allelic balance at the other marker on 19q.

Taken together, 29 out of 51 (57\%) informative tumours exhibited LOH of at least one marker on both $1 \mathrm{p}$ and 19q. Three tumours (B6, B17 and B14) had 1p LOH in the absence of detectable $19 \mathrm{q} \mathrm{LOH}$, whereas four tumours (A9, A22, B10 and B20) exhibited $19 \mathrm{q}$ LOH but no $1 \mathrm{p}$ LOH.

\section{Statistical analysis}

The $1 \mathrm{p}$ and $19 \mathrm{q}$ allelic status was correlated with clinicopathological parameters. 1p LOH was found to be closely associated with $19 \mathrm{q}$ LOH in OTs $(P<0.0001)$. No statistical significance was observed between 1p LOH, 19q LOH or combined 1p/19q LOH and patient's gender, tumour type or grade. All six OTs with interstitial deletion on 1 p 36.3 were of WHO grade II, but only a trend was seen between interstitial deletion and tumour grade $(P=0.065)$.

\section{DISCUSSION}

Recurrent deletion of chromosome 1p in OTs strongly implies the presence of tumour suppressor gene(s) on this chromosome arm. With an aim to isolate the tumour suppressor gene by positional cloning approach, we set out to map the minimally deleted regions on the $1 \mathrm{p}$ arm. A series of 52 OTs were examined for allelic deletion by two rounds of microsatellite analysis followed by confirmation with FISH. Six tumours were found to harbour small interstitial deletion specifically on 1p36.3. Previous deletion mapping studies had revealed a few OTs with interstitial deletion on $1 \mathrm{p}$, thus hindering a precise mapping of the critical deletion region (Husemann et al, 1999; Smith et al, 1999). This was likely due to the limited number of markers examined and to the wider genetic spacing of these markers. By examining more closely spaced markers on 1 p36 in our microsatellite analysis, we were able to detect interstitial deletion in $12 \%$ of our tumour series. The proportion of tumours with interstitial deletion on $1 \mathrm{p}$ is likely to be an underestimation, as other previously defined deletion regions were not subject to high-resolution mapping as in this study. The small overlapping intervals on 1 p 36.3 have allowed us to delineate two contiguous MDRs, which fall in the overlapped region of deletion defined by Smith et al (1999) and Husemann et al (1999), providing further evidence that the 1 p36.3 region is involved in tumorigenesis of OTs. Moreover, our deletion mapping study has narrowed down the critical deletion region on 1 p36.3 to $\sim 1.2 \mathrm{Mb}$. This genomic region has been sequenced almost to entirety with a small sequence gap, for which no genomic clones are available. There are eight genes annotated in the MDRs (Table 1). Of these genes, only TP73, DFFB and SHREW1 have been studied previously.

The TP73 gene encodes product that shares significant structural and functional homology with the p53 tumour suppressor, raising the possibility that $\mathrm{p} 73$ might be a putative tumour suppressor (reviewed in Melino et al, 2002). Indeed, functional studies have revealed that $\mathrm{p} 73$ has antiproliferative and proapoptotic activity, independent of p53 status (Zhu et al, 1998a; Yuan et al, 1999). However, unlike TP53, somatic mutation of TP73 in human cancer is very rare (Mai et al, 1998; Alonso et al, 2001; Dong et al, 2002; Melino et al, 2002), suggesting that p73 does not act as a classical Knudson-type tumour suppressor. When transcript levels were examined, TP73 was found to be overexpressed in a variety of tumours (Tannapfel et al, 1999; Zaika et al, 1999), but its expression is reduced or absent in certain haematological malignancies (Corn et al, 1999; Kawano et al, 1999). Such downregulation of transcription is attributed to promoter hypermethylation (Corn et al, 1999; Kawano et al, 1999). In OTs, promoter hypermethylation of TP73 is detectable in $8-24 \%$ of tumours and anaplastic tumours are more common to harbour such aberration (Dong et al, 2001; Watanabe et al, 2002; Alonso et al, 2003). The TP73 methylation status has also been associated with decreased level of TP73 transcript (Dong et al, 2002). Taken together, these data suggest that p73 is involved in a subset of OTs. However, the recent discovery of N-terminal truncated isoforms of $\mathrm{p} 73$, namely $\Delta \mathrm{Np} 73$, has provided new insights into the role of p73 plays in tumorigenesis. Functional studies showed that $\triangle \mathrm{Np} 73$ is a transdominant inhibitor of wildtype p53 and p73 by counteracting their target gene transactivation, apoptosis and growth suppression and is able to immortalise primary mouse embryo fibroblasts in vitro (Grob et al, 2001; Nakagawa et al, 2002; Stiewe et al, 2002; Petrenko et al, 2003). These data demonstrate that $\Delta \mathrm{Np} 73$ acts as an oncogene and has opposing activity of $\mathrm{p} 73$. Given the diverse function of $\mathrm{p} 73$ 
isoforms, it is thus of paramount importance to resolve the functional contribution of each isoform toward cancer development.

DFFB is the other known gene identified in MDR1. It encodes the caspase-activated DNase and is responsible for degradation of chromosomal DNA during apoptosis. Its gene product is complexed with an inhibitor encoded by DFFA in vivo. Upon apoptosis induction, caspase cleaves the inhibitor and releases DFFB from the complex to enter into nuclei to degrade chromosomal DNA (Nagase et al, 2003). No somatic mutations of DFFB were detected in 41 neuroblastomas examined (Judson et al, 2000). However, aberrant DFFB transcripts resulting from splicing have been reported in hepatocellular carcinoma (Hsieh et al, 2003).

SHREW1 appears to be the single gene located in MDR2. Recently, the cDNA of SHREW1 was isolated from invasive endometriotic cells (Bharti et al, 2004). This gene encodes a $\sim 48 \mathrm{kDa}$ transmembrane protein, with its carboxy terminus being cytoplasmic, and does not belong to any protein family. Ectopic expression of SHREW1 in polarised epithelial cells showed that shrew1 protein colocalised with E-cadherin in adherens junctions, probably via binding of $\beta$-catenin. However, in nonpolarised invasive epithelial cells, shrew1 bound neither to N-cadherin and $\beta$-catenin (Bharti et al, 2004). E-cadherin is generally not expressed in brain tumours, except in benign meningiomas (Schwechheimer et al, 1998), whereas $\mathrm{N}$-cadherin and $\beta$-catenin are detectable at cell-cell junctions in malignant astrocytic tumours (Utsuki et al, 2002). The $\mathrm{N}$-cadherin and $\beta$-catenin status in OT is not known. Further investigation of SHREW1 function may shed light on the role of this gene plays in cancer development and its involvement in invasion.

In conclusion, our deletion mapping study has refined one of the candidate tumour suppressor loci on chromosome arms $1 \mathrm{p}$ in OTs. Two contiguous MDRs are delineated from a small interval on 1p36.3, between D1S468 and D1S1608, which contain only eight known and novel genes. These candidate genes are currently under investigation for their involvement in OTs.

\section{Note added in proof}

A recent report by Felsberg et al (Brain Pathology 2004;14: 121-130) marked one of the commonly deleted regions to $1 \mathrm{p} 36.31$ pter in oligodendroglial tumours. Their results are in line with our findings.

\section{ACKNOWLEDGEMENTS}

This study was supported by the Research Grant Council of Hong Kong and the Chinese University of Hong Kong.

\section{REFERENCES}

Alonso ME, Bello MJ, Gonzalez-Gomez P, Arjona D, Lomas J, de Campos JM, Isla A, Sarasa JL, Rey JA (2003) Aberrant promoter methylation of multiple genes in oligodendrogliomas and ependymomas. Cancer Genet Cytogenet 144: $134-142$

Alonso ME, Bello MJ, Gonzalez-Gomez P, Lomas J, Arjona D, de Campos JM, Kusak ME, Sarasa JL, Isla A, Rey JA (2001) Mutation analysis of the p73 gene in nonastrocytic brain tumours. Br J Cancer 85: 204-208

Bello MJ, de Campos JM, Vaquero J, Kusak ME, Sarasa JL, Rey JA (2000b) High-resolution analysis of chromosome arm 1p alterations in meningioma. Cancer Genet Cytogenet 120: 30-36

Bello MJ, de Campos JM, Vaquero J, Ruiz-Barnes P, Kusak ME, Sarasa JL, Rey JA (2000a) hRAD54 gene and 1p high-resolution deletion-mapping analyses in oligodendrogliomas. Cancer Genet Cytogenet 116: $142-147$

Bello MJ, Leone PE, Vaquero J, de Campos JM, Kusak ME, Sarasa JL, Pestana A, Rey JA (1995) Allelic loss at 1p and 19q frequently occurs in association and may represent early oncogenic events in oligodendroglial tumors. Int J Cancer 64: 207-210

Bharti S, Handrow-Metzmacher H, Zickenheiner S, Zeitvogel A, Baumann R, Starzinski-Powitz A (2004) A novel membrane protein shrew-1 target to cadherin-mediated junctions in polarized epithelial cells. Mol Biol Cell 15: $397-406$

Bigner SH, Matthews MR, Rasheed BK, Wiltshire RN, Friedman HS, Friedman AH, Stenzel TT, Dawes DM, McLendon RE, Bigner DD (1999) Molecular genetic aspects of oligodendrogliomas including analysis by comparative genomic hybridization. Am J Pathol 155: 375-386

Cairncross JG, Ueki K, Zlatescu MC, Lisle DK, Finkelstein DM, Hammond RR, Silver JS, Stark PC, Macdonald DR, Ino Y, Ramsay DA, Louis DN (1998) Specific genetic predictors of chemotherapeutic response and survival in patients with anaplastic oligodendrogliomas. J Natl Cancer Inst 90: $1473-1479$

Corn PG, Kuerbitz SJ, van Noesel MM, Esteller M, Compitello N, Baylin SB, Herman JG (1999) Transcriptional silencing of the p73 gene in acute lymphoblastic leukemia and Burkitt's lymphoma is associated with $5^{\prime}$ CpG island methylation. Cancer Res 59: $3352-3356$

Dong SM, Pang JC, Hu J, Zhou LF, Ng HK (2002) Transcriptional inactivation of TP73 expression in oligodendroglial tumors. Int J Cancer 98: $370-375$

Dong SM, Pang JC, Poon WS, Hu J, To KF, Chang AR, Ng HK (2001) Concurrent hypermethylation of multiple genes is associated with grade of oligodendroglial tumors. J Neuropathol Exp Neurol 60: 808-816

Grob TJ, Novak U, Maisse C, Barcaroli D, Luthi AU, Pirnia F, Hugli B, Graber HU, De Laurenzi V, Fey MF, Melino G, Tobler A (2001) Human delta Np73 regulates a dominant negative feedback loop for TAp73 and p53. Cell Death Differ 8: $1213-1223$

He J, Hoang-Xuan K, Marie Y, Leuraud P, Mokhtari K, Kujas M, Delattre JY, Sanson M (2000) P18 tumor suppressor gene and progression of oligodendrogliomas to anaplasia. Neurology 55: $867-869$

Hsieh SY, Liaw SF, Lee SN, Hsieh PS, Lin KH, Chu CM, Liaw YF (2003) Aberrant caspase-activated DNase (CAD) transcripts in human hepatoma cells. Br J Cancer 88: 210-216

Husemann K, Wolter M, Buschges R, Bostrom J, Sabel M, Reifenberger G (1999) Identification of two distinct deleted regions on the short arm of chromosome 1 and rare mutation of the CDKN2C gene from $1 \mathrm{p} 32$ in oligodendroglial tumors. J Neuropathol Exp Neurol 58: $1041-1050$

Ino Y, Betensky RA, Zlatescu MC, Sasaki H, Macdonald DR, StemmerRachamimov AO, Ramsay DA, Cairncross JG, Louis DN (2001) Molecular subtypes of anaplastic oligodendroglioma: implications for patient management at diagnosis. Clin Cancer Res 7: 839-845

Iuchi T, Namba H, Iwadate Y, Shishikura T, Kageyama H, Nakamura Y, Ohira M, Yamaura A, Osato K, Sakiyama S, Nakagawara A (2002) Identification of the small interstitial deletion at chromosome band 1 p34-p35 and its association with poor outcome in oligodendroglial tumors. Genes Chromosomes Cancer 35: 170-175

Jenkins RB, Qian J, Lieber MM, Bostwick DG (1997) Detection of c-myc oncogene amplification and chromosomal anomalies in metastatic prostatic carcinoma by fluorescence in situ hybridization. Cancer Res 57: $524-531$

Jeuken JW, Sprenger SH, Wesseling P, Macville MV, von Deimling A, Teepen HL, van Overbeeke JJ, Boerman RH (1999) Identification of subgroups of high-grade oligodendroglial tumors by comparative genomic hybridization. J Neuropathol Exp Neurol 58: 606-612

Judson H, van Roy N, Strain L, Vandesompele J, Van Gele M, Speleman F, Bonthron DT (2000) Structure and mutation analysis of the gene encoding DNA fragmentation factor 40 (caspase-activated nuclease), a candidate neuroblastoma tumour suppressor gene. Hum Genet 106: $406-413$

Kawano S, Miller CW, Gombart AF, Bartram CR, Matsuo Y, Asou H, Sakashita A, Said J, Tatsumi E, Koeffler HP (1999) Loss of p73 gene expression in leukemias/lymphomas due to hypermethylation. Blood 94: $1113-1120$

Macdonald DR, Gaspar LE, Cairncross JG (1990) Successful chemotherapy for newly diagnosed aggressive oligodendroglioma. Ann Neurol 27: 573-574

Mai M, Huang H, Reed C, Qian C, Smith JS, Alderete B, Jenkins R, Smith DI, Liu W (1998) Genomic organization and mutation analysis of p73 in 
oligodendrogliomas with chromosome 1 p-arm deletions. Genomics 51: $359-363$

Melino G, De Laurenzi V, Vousden KH (2002) p73: friend or foe in tumorigenesis. Nat Rev Cancer 2: 605-615

Nagase H, Fukuyama H, Tanaka M, Kawane K, Nagata S (2003) Mutually regulated expression of caspase-activated DNase and its inhibitor for apoptotic DNA fragmentation. Cell Death Differ 10: 142-143

Nakagawa T, Takahashi M, Ozaki T, Watanabe Ki K, Todo S, Mizuguchi H, Hayakawa T, Nakagawara A (2002) Autoinhibitory regulation of p73 by Delta Np73 to modulate cell survival and death through a p73-specific target element within the Delta Np73 promoter. Mol Cell Biol 22: 2575-2585

Perry JR, Louis DN, Cairncross JG (1999) Current treatment of oligodendrogliomas. Arch Neurol 56: 434-436

Petrenko O, Zaika A, Moll UM (2003) DeltaNp73 facilitates cell immortalization and cooperates with oncogenic Ras in cellular transformation in vivo. Mol Cell Biol 23: 5540-5555

Pohl U, Cairncross JG, Louis DN (1999) Homozygous deletions of the CDKN2C/p18INK4C gene on the short arm of chromosome 1 in anaplastic oligodendrogliomas. Brain Pathol 9: 639-643

Reifenberger G, Kros JM, Burger P, Louis DN, Collins VP (2000) Oligodendroglioma. In Pathology and Genetics of Tumors of the Nervous System Kleihues P, Cavenee WK (eds) pp 56-67, Lyon: IARC Press

Reifenberger J, Reifenberger G, Liu L, James CD, Wechsler W, Collins VP (1994) Molecular genetic analysis of oligodendroglial tumors shows preferential allelic deletions on $19 \mathrm{q}$ and 1p. Am J Pathol 145: $1175-1190$

Sasaki H, Zlatescu MC, Betensky RA, Ino Y, Cairncross JG, Louis DN (2001) PTEN is a target of chromosome $10 \mathrm{q}$ loss in anaplastic oligodendrogliomas and PTEN alterations are associated with poor prognosis. Am Pathol 59: 359-367

Schwechheimer K, Zhou L, Birchmeier W (1998) E-Cadherin in human brain tumours: loss of immunoreactivity in malignant meningiomas. Virchows Arch 432: $163-167$

Smith JS, Alderete B, Minn Y, Borell TJ, Perry A, Mohapatra G, Hosek SM, Kimmel D, O'Fallon J, Yates A, Feuerstein BG, Burger PC, Scheithauer BW, Jenkins RB (1999) Localization of common deletion regions on $1 p$ and $19 \mathrm{q}$ in human gliomas and their association with histological subtype. Oncogene 18: $4144-4152$
Stiewe T, Zimmermann S, Frilling A, Esche H, Putzer BM (2002) Transactivation-deficient deltaTA-p73 acts as an oncogene. Cancer Res 62: $3598-3602$

Tannapfel A, Wasner M, Krause K, Geissler F, Katalinic A, Hauss J, Mossner J, Engeland K, Wittekind C (1999) Expression of p73 and its relation to histopathology and prognosis in hepatocellular carcinoma. $J$ Natl Cancer Inst 91: 1154-1158

Tong CY, Zheng PP, Pang JC, Poon WS, Chang AR, Ng HK (2001) Identification of novel regions of allelic loss in ependymomas by highresolution allelotyping with 384 microsatellite markers. J Neurosurg 95: 9-14

Utsuki S, Sato Y, Oka H, Tsuchiya B, Suzuki S, Fujii K (2002) Relationship between the expression of E-, N-cadherins and beta-catenin and tumor grade in astrocytomas. J Neurooncol 57: 187-192

Watanabe T, Huang H, Nakamura M, Wischhusen J, Weller M, Kleihues P, Ohgaki H (2002) Methylation of the p73 gene in gliomas. Acta Neuropathol 104: $357-362$

Watanabe T, Nakamura M, Yonekawa Y, Kleihues P, Ohgaki H (2001a) Promoter hypermethylation and homozygous deletion of the p14ARF and p16INK4a genes in oligodendrogliomas. Acta Neuropathol 101: 185-189

Watanabe T, Yokoo H, Yokoo M, Yonekawa Y, Kleihues P, Ohgaki H (2001b) Concurrent inactivation of RB1 and TP53 pathways in anaplastic oligodendrogliomas. J Neuropathol Exp Neurol 60: 1181 - 1189

Wolter M, Reifenberger J, Blaschke B, Ichimura K, Schmidt EE, Collins VP, Reifenberger G (2001) Oligodendroglial tumors frequently demonstrate hypermethylation of the CDKN2A (MTS1, p16INK4a), p14ARF, and CDKN2B (MTS2, p15INK4b) tumor suppressor genes. J Neuropathol Exp Neurol 60: $1170-1180$

Yuan ZM, Shioya H, Ishiko T, Sun X, Gu J, Huang YY, Lu H, Kharbanda S, Weichselbaum R, Kufe D (1999) p73 is regulated by tyrosine kinase c-Abl in the apoptotic response to DNA damage. Nature 399: 814-817

Zaika AI, Kovalev S, Marchenko ND, Moll UM (1999) Overexpression of the wild type p73 gene in breast cancer tissues and cell lines. Cancer Res 59: $3257-3263$

Zhu J, Jiang J, Zhou W, Chen X (1998a) The potential tumor suppressor p73 differentially regulates cellular p53 target genes. Cancer Res 58: $5061-5065$

Zhu JJ, Santarius T, Wu X, Tsong J, Guha A, Wu JK, Hudson TJ, Black PM (1998b) Screening for loss of heterozygosity and microsatellite instability in oligodendrogliomas. Genes Chromosomes Cancer 21: 207-216 